\title{
J. Miélot, Vie de sainte Katherine
}

\section{Anne Schoysman}

\section{(2) OpenEdition}

\section{Journals}

\section{Édition électronique}

URL : http://journals.openedition.org/studifrancesi/9903

DOI : 10.4000/studifrancesi.9903

ISSN : 2427-5856

\section{Éditeur}

Rosenberg \& Sellier

\section{Édition imprimée}

Date de publication : 1 août 2017

Pagination : 341-342

ISSN : 0039-2944

\section{Référence électronique}

Anne Schoysman, « J. Miélot, Vie de sainte Katherine », Studi Francesi [En ligne], 182 (LXI | II) | 2017, mis en ligne le 01 août 2017, consulté le 06 janvier 2021. URL : http://journals.openedition.org/ studifrancesi/9903 ; DOI : https://doi.org/10.4000/studifrancesi.9903

Ce document a été généré automatiquement le 6 janvier 2021.

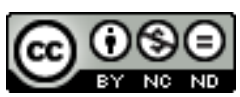

Studi Francesi è distribuita con Licenza Creative Commons Attribuzione - Non commerciale - Non opere derivate 4.0 Internazionale. 


\title{
J. Miélot, Vie de sainte Katherine
}

\author{
Anne Schoysman
}

\section{RÉFÉRENCE}

JEAN MIÉLOT, Vie de sainte Katherine, édition de Maria Colombo Timelli, Paris, Classiques Garnier, 2015, «Textes littéraires du Moyen Âge» 34, 276 pp.

$1 \quad$ La Vie de sante Katherine, rédigée en prose par Jean Miélot en 1457, est conservée dans deux témoins: le ms. Paris, BnF, fr. 6449 (M, texte vraisemblablement correspondant de près à la version de Miélot quoique l'autographie du ms. ne soit pas établie), destiné à Philippe le Bon et illustré de semi-grisailles dues pour la plupart à Willem Vrelant; et le ms. Paris, BnF, n.a.fr. 28650 (D), copie réalisée probablement vers 1475 par David Aubert à la demande de Marguerite d'York, illustré par Simon Marmion. Ces manuscrits, reproduits tous deux sur Gallica, témoignent à la fois de la fervente production de livres de luxe qui a caractérisé la cour de Bourgogne, et de la dévotion dont a joui sainte Catherine d'Alexandrie, l'une des saintes les plus honorées en France et en Bourgogne au XV $\mathrm{X}^{\mathrm{e}}$.

2 Attentif à donner une version exhaustive de la Vie de sainte Catherine, Miélot traduit la compilation d'un certain Frater Petrus, qui a vécu en Toscane au XIII ${ }^{\mathrm{e}} \mathrm{s}$. Comme c'est généralement le cas, la source directe de Miélot nous échappe, aucun manuscrit de la compilation de Frater Petrus n'ayant subsisté. Son texte a toutefois été imprimé à partir de 1500 (Nova quedam singularis atque rara legenda ex aliis sex legendis collecta et perfecta [...], Strasbourg, Johann Grüninger, ISTC ip00427000), et M.C.T. montre tout le parti que l'on peut tirer de cet imprimé ancien pour cerner la source de Miélot et les traits caractéristiques de sa traduction: fidélité au latin, présence de nombreux calques morphologiques, sémantiques, syntaxiques, mais volonté évidente de donner à lire un texte qui ne soit pas obscur, notamment avec l'ajout de gloses traductives pour les realia du monde romain.

3 L'intérêt de la seconde copie du texte (ms. D), réalisée environ vingt ans plus tard et malheureusement mutilée des trois premiers cahiers (prologues et 22 premiers 
chapitres), réside dans la technique de réécriture de David Aubert, qui se confirme ici enclin à l'amplification, à l'ajout de binômes coordonnés, d'adverbes ou d'attributs de tous genres. Sur le plan philologique, des cas de convergence de la source latine et de D permettent de corriger certaines erreurs mécaniques de $\mathrm{M}$ et de prouver un archétype commun à $\mathrm{M}$ et $\mathrm{D}$, mais $\mathrm{D}$ ne recourt jamais au texte latin pour corriger les erreurs traductives de $\mathrm{M}$, et introduit quelques erreurs individuelles (l'hypothèse avancée par M.C.T. d'une version intermédiaire entre l'archétype de la traduction et $\mathrm{D}$, plausible en raison de la distance temporelle, reste une alternative douteuse basée sur deux passages où $\mathrm{M}$ et $\mathrm{D}$ semblent tous deux corrompus). Si le choix de baser l'édition critique du texte sur le ms. M s'impose donc, l'éditrice souligne la nécessité de n'écarter a priori ni le contrôle du texte latin, quoique dans une version imprimée de près d'un demi-siècle plus tardive, ni la copie d'Aubert, fortement innovatrice. Remarquons qu'il s'agit là d'une situation commune à de nombreuses traductions de la seconde moitié du $\mathrm{xv}^{\mathrm{e}}$ s., qui exige une solution éditoriale susceptible de rendre compte de l'apport philologique d'une «tradition» textuelle dont chaque élément (le texte latin, le ms. M, la copie amplifiée de D) est fortement autonome. La solution éditoriale choisie par M.C.T. emporte la conviction: elle offre l'édition des deux rédactions, celle de $\mathrm{M}$ et celle de $\mathrm{D}$, avec une même numérotation des chapitres afin de faciliter leur lecture en regard; et outre l'apparat critique, normalement enregistré en bas de page, elle choisit très opportunément de regrouper à la fin de chaque chapitre des notes qui fournissent les éléments historiques nécessaires à éclairer le texte et commentent systématiquement les rapports entre les deux mss de la version française, et entre ceux-ci et le texte latin attentivement collationné. Étant donné que les chapitres sont relativement courts, cette formule a le mérite non seulement de définir par contraste les caractéristiques linguistiques et stylistiques de la version éditée, mais aussi de permettre de saisir facilement la profondeur de la «tradition» du texte, là où le second ms. français et surtout le texte latin sont des éléments trop hybrides pour pouvoir être accueillis dans l'apparat critique.

4 L'étude linguistique, fondée sur un dépouillement exhaustif, se concentre sur les régionalismes et révèle que la copie de David Aubert est plus marquée que le texte du ms. M par des traits du Nord et du Nord-Est. Le Glossaire, qui signale quelques formes propres au ms. D, donne aussi, le cas échéant, la forme latine traduite. Trois annexes complètent le volume: les Vies de sainte Catherine rédigées au $\mathrm{xv}^{\mathrm{e}} \mathrm{s}$. recensées dans la base Jonas de l'IRHT (liste qui n'a pas été modifiée depuis la parution du volume); les titres de chapitres, caractérisés par une évidente recherche de variété, d'où ressort la technique d'amplification et de multiplication des rubriques par David Aubert; enfin, l'édition de la vie de sainte Catherine dans la version du Martyrologe (Bruxelles, KBR, mss 9946-9948, ff. 120v-123v), une version brève qui inclut une traduction libre de la Legenda aurea, où sont encore relevés quelques picardismes et archaïsmes. L'intérêt du volume dépasse donc largement celui de l'édition de la traduction de Jean Miélot confrontée avec la copie amplifiée de David Aubert: une perspective élargie, sur le plan philologique, linguistique et historique, éclaire la production textuelle de la cour de Bourgogne et les aspects régionaux de ces textes, qui s'insèrent dans le courant de la dévotion à sainte Catherine d'Alexandrie jusqu'à la diffusion imprimée de la compilation latine traduite par le secrétaire de Philippe le Bon. 